times incisively about environmental issues, Budiansky consistently misses the big questions. There are difficult ethical and economic choices in how we value biological diversity. Those who manage this diversity face not only scientific uncertainty but also the knowledge that their actions may take decades to unfold, time in which society's values may change. Scientists who predict high future extinction rates are not omniscient, but believe, simply, that ignorance is not bliss. How sad that Budiansky misses the chance to write thoughtfully about the interfaces between nature, ethics, economics and our future.

Stuart L. Pimm is in the Department of Ecology and Evolutionary Biology, University of Tennessee, Knoxville, Tennessee 37996, USA.

\section{Ways of seeing}

\section{David Knight}

\section{A History of Scientific Thought: Elements of a History of Science. Edited by Michel Serres. Blackwell: 1995. Pp. 760. £75, \$100.}

THEY order things differently in France, and it is good for outsiders to see how things look there. Although the dust jacket has a portrait of Michael Faraday in his laboratory, inside he makes only a passing appearance in one sentence (like God in the Origin of Species); the book does not cover everything. It is striking that we do not get to Galileo until page 280 , and to the nineteenth century until about page 400: despite the exponential growth of science, the focus is on beginnings. The book is not intended as a work of reference; rather, it is a series of meditative or considered essays, examining nodal points in the long history of science from the first emergence of experts writing on clay in Babylonia.

Michel Serres himself evokes the beginnings of geometry in Greece and then in an impressionistic tour de force calls up the Paris of the years around 1800 when it was the centre of excellence in all the sciences. He sketches the emergence of scientists as a kind of secular clergy; the shade of Auguste Comte indeed stalks through the book, and we learn about his calendar where the saints are men of science, as well as the Revolutionary calendar with its tenday weeks. Serres is bold enough to paint for us the dazzling big picture, the general plan, whereas most Anglo-Saxons, perhaps in our Baconian tradition, are more like bricklayers than architects in constructing the historical edifice.

Where it comes off, this is very splendid; and the various authors do their best to show how the events they describe are

nodal, rather like the poet-scientist $\mathbf{J}$. W. Goethe's Ur-phenomena. They do their best also to show the unexpected, the nonteleological in the history of the sciences. We know that if Humphry Davy had not isolated potassium when he did, J. J. Berzelius would have done so within a year or two; and if he had not subsequently declared the elementary nature of chlorine, then J. L. Gay-Lussac would soon have done that. There is something like inevitability in the development of science;

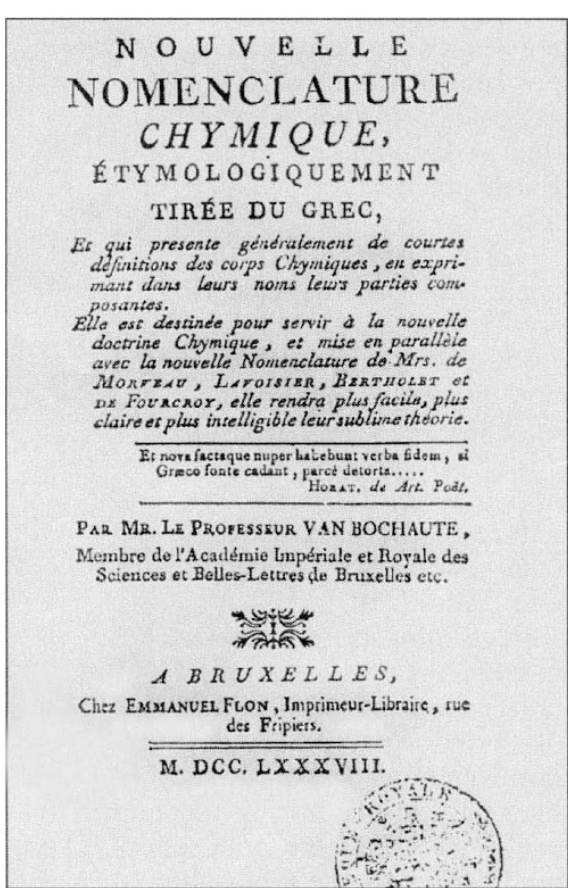

1789-1914, where specialization and exponential growth were the order of the day, the focus is on individuals: A. L. Lavoisier, Charles Lyell, Gregor Mendel and D. I. Mendeleyev. These are not surprising names, except perhaps that they include no classical physicists; there is no attempt here to revise the pantheon. Geof Bowker gives us a close textual analysis of Lyell's writing; Bernadette Bensaude-Vincent brings her usual clarity and sharpness to her studies of the chemists, placing them carefully in con-

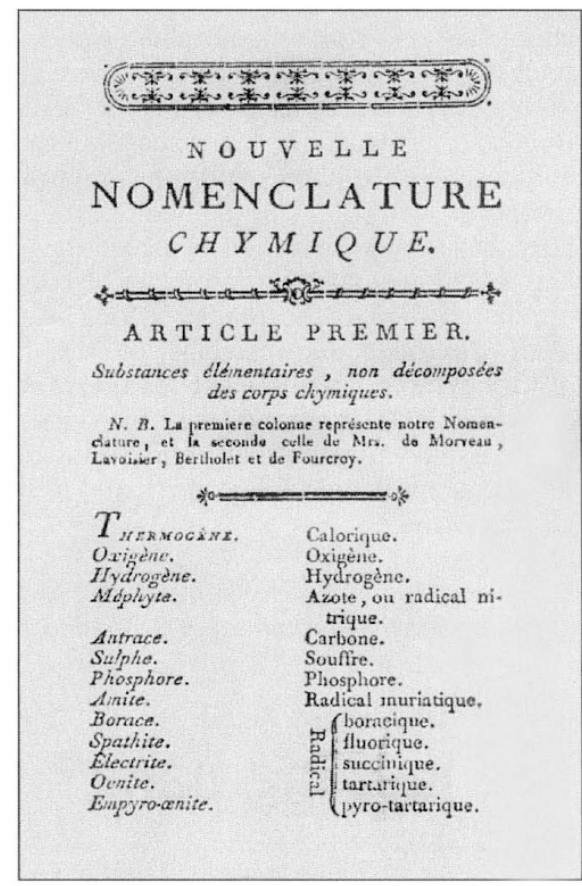

Cover and page of the Flemish chemist Karel van Bochaute's Nouvelle Nomenclature (1788). From Lavoisier in European Context: Negotiating a New Language for Chemistry edited by Bernadette Bensaude-Vincent and Ferdinando Abbri. Science History Publications, \$45.95.

but there is also the contingent, as these authors emphasize. Close examination of social context and of personal careers certainly diminishes our belief in progress and inevitability: we all know how important opportunism and career development can be. These authors take history seriously.

We find here some excellent storytelling; for example from Michel Aulthier on Archimedes, warfare and science, and from Bruno Latour on Louis Pasteur, Felix Pouchet and spontaneous generation. Others give us lucid straightforward accounts without many surprises, such as James Ritter on early mathematics, Paul Benôit and Françoise Micheau on Arab science, or Jean-Marc Drouin on naturalists and travellers. Some wear their learning lightly, such as Catherine Goldstein writing elegantly about mathematics moving from marginalia by amateurs to journal articles by professionals as Homo ludens gives way to Homo faber. Some, such as Isabelle Stengers, have written something like essay reviews for a learned journal, in her case about recent studies of Galileo, which are closer to meta-history than to narrative.

For the long nineteenth century, text - as does Drouin with Mendel, where reality and myth are particularly intertwined. These are 'exemplary' essays giving us some clues in our approach to their century; but in contrast to its close studies of the early and mediaeval periods, the book is thin in its coverage of the time when disciplines and professions were emerging, and the frontiers between sciences were being established and policed. Societies, journals, university departments, medical schools as midwives of biology and chemistry, great exhibitions, lectures stimulating the public understanding of science, addressed to the élite or to working men we learn very little of all this.

And for the twentieth century, we have a close study of devices for the oil industry; an interesting story of Frédéric Joliot and the intersection of science with politics and war; and a carefully contextual history of the computer by Pierre Lévy emphasizing the different roles played by different people with different ends, in a complex story in which one should not look for some crucial and datable foundationmoment. Here, as in the previous chapters, this approach keeps the book open for the 
reader without a modern scientific training; as an account of the science of our century it clearly does not give any kind of coverage, but it does indicate seminal points. Joliot on atomic weapons has contemporary resonance, but it is perhaps surprising that there is no sequel to the naturalists or to Mendel, given the importance for us of ecology and genetics.

We thus have a book full of stimulating insights, something to be recommended to students or to the general reader who has some idea of what science is and was about. We find some memorable episodes such as the mediaeval attempt to make theology a science, as described by Paul Benôit; but probably for scientists, the emphasis on beginnings and times remote from our own will make the book particularly desirable. These lively accounts and the anonymous translator is to be congratulated - take the reader a long way from the brief run-throughs of recent history to be found in science textbooks or encyclopaedias. And the book also gives professionals in history and philosophy of science something to engage with; it is very welcome.

David Knight is in the Department of Philosophy, University of Durham, 50 Old Elvet, Durham DH1 3HN, UK.

\section{The last big bang?}

Mike A'Hearn

\begin{abstract}
Rogue Asteroids and Doomsday Comets: The Search for the Million Megaton Menace that Threatens Life on Earth. By Duncan Steel. Wiley: 1995. Pp. 308. \$24.95, £16.99.
\end{abstract}

WiLl we or our descendants all die when an extraterrestrial object comes hurtling down onto Earth? This question was brought to the fore by the enormous publicity surrounding the collision of the fragments of comet Shoemaker-Levy 9 with Jupiter in July 1994. Even before these events, the question had stimulated some astronomers to propose searches to identify all large asteroids that might hit Earth in the foreseeable future. The question had also stimulated developers of nuclear weapons to propose mechanisms for deflecting such asteroids before they collide with Earth. At the behest of the US Congress, NASA has appointed several committees to consider detection and deflection of potentially hazardous asteroids, the most recent of which, the Shoemaker Committee, has just released its report. Meanwhile, the International Astronomical Union has also appointed a working group to consider what actions are scientifically appropriate in studying and detecting
near-Earth objects.

As someone engaged on the periphery of this issue, it seems clear to me that certain aspects of the problem have been investigated thoroughly and are well understood, whereas others have been almost ignored and so are not understood. It is technically possible to carry out a search, on a timescale of ten years or so, to detect 90 per cent of the near-Earth asteroids with radii greater than $1 \mathrm{~km}$ that might hit Earth in the foreseeable future.

On the other hand, the hazard due to long-period comets is poorly understood and we do not know how to detect these more than a year or two in advance. Similarly, we do not fully understand the nature of the hazard even from asteroids of a given size. Studies of last year's Jupiter impacts (discussed in a lengthy epilogue to the book) show the importance of a process previously not even considered: when material ejected during the impact falls back down onto the atmosphere, it dramatically heats the atmosphere over very large areas.

It is also unclear how the public views the risk of an extraterrestrial impact compared with that of, say, an acroplane crash. Statistically, the risks of death from the two causes would seem to be of the same order of magnitude. Extraterrestrial impacts are, of course, much less frequent but have a dramatically greater effect, leading to a huge uncertainty in the actual number of deaths as well as a notable difference in public perception of the risk.

Steel aims to heighten public awareness of the risk and thus develop political support for funding the searches and other studies that might ultimately allow us to save ourselves or our descendants from a worldwide catastrophe. He writes about facts that are accepted by most astronomers and ideas that are wildly speculative, as well as about everything in between. There are vast uncertainties in many of the predictions and he points out many areas where astronomers are in disagreement. Examples of past impacts include the generally understood small impacts, such as Meteor Crater in Arizona and the explosion above Tunguska in 1908 , but Steel also writes about other impacts, the effects of which are not so widely accepted. It seems to me that most astronomers accept the theory that the impact that created the Chicxulub crater in the Yucatan also caused the extinction of the dinosaurs at the end of the Cretaceous period, although this is apparently less widely accepted among palaeontologists, some of whom still argue for a more gradual extinction. Unclear to both astronomers and palaeontologists is whether large craters and extinctions are really periodic.

With its wide range of speculation, every scientist, whether astronomer or geologist, palaeontologist or archaeologist, will disagree with one or another of the suggestions in this engaging and worthwhile book. Steel's proposal that the Taurid meteor showers sparked off the building of the first stage of Stonehenge will certainly charge up many readers, some positively and others negatively. This is, of course, his purpose in writing the book - to encourage others to think about the problem. The basic question is whether we should be terrified at the prospect of a large impact. Should we spend the money now to begin the search for potential impact objects and find out more about this particular hazard - a hazard that is undoubtedly real but of uncertain magnitude?

Mike A'Hearn is at the Astronomy Program, University of Maryland, Stadium Drive, College Park, Maryland 20742, USA. 